Article

\title{
The Effect of a Renewable Energy Certificate Incentive on Mitigating Wind Power Fluctuations: A Case Study of Jeju Island
}

\author{
Woong Ko ${ }^{1}$, Jaeho Lee ${ }^{1}$ and Jinho Kim ${ }^{2, *}$ \\ 1 Research Institute for Solar and Sustainable Energies, Gwangju Institute of Science and Technology, \\ 123 Cheomdangwagi-ro, Buk-gu, Gwangju 61005, Korea; kwoong2001@gist.ac.kr (W.K.); \\ jaeholee@buffalo.edu (J.L.) \\ 2 School of Integrated Technology, Gwangju Institute of Science and Technology, 123 Cheomdangwagi-ro, \\ Buk-gu, Gwangju 61005, Korea \\ * Correspondence: jeikim@gist.ac.kr; Tel./Fax: +82-62-715-5322
}

Received: 11 March 2019; Accepted: 18 April 2019; Published: 20 April 2019

\begin{abstract}
As renewable energy penetration in power systems grows, adequate energy policies are needed to support the system's operations with flexible resources and to adopt more sustainable energies. A peak-biased incentive for energy storage systems (ESS) using the Korean renewable portfolio standard could make power system operations more difficult. For the first time in the research, this study evaluates the effect of imposing a renewable energy certificate incentive in off-peak periods on mitigating wind power fluctuations. We design a coordinated model of a wind farm with an ESS to model the behavior of wind farm operators. Optimization problems are formulated as mixed integer linear programming problems to test the implementation of revenue models under Korean policy. These models are designed to consider additional incentives for discharging the ESS during off-peak periods. The effects of imposing the incentives on wind power fluctuations are evaluated using the magnitude of the renewable energy certificate (REC) multiplier.
\end{abstract}

Keywords: renewable portfolio standard; renewable energy certificate; wind farm; energy storage system; variation criteria; mixed integer linear programming

\section{Introduction}

As global energy policies try to reduce the use of conventional fuel-based generators, the rate of renewable energy penetration has increased. Following global trends, South Korea has adopted a renewable portfolio standard (RPS) to promote the utilization of sustainable energies. In 2012, renewable promotion policies, such as feed-in tariffs (FITs), subsidized renewable energy owners, regardless of the actual power generation. The shift from FITs to the RPS was due to a financial shortage. In order to solve this problem, the RPS was designed to impose renewable energy generation obligations on large suppliers instead of offering unconditional energy subsidies [1]. Within this policy, renewable energy owners can retrieve their investment by obtaining a renewable energy certificate (REC) credit for the actual generation and selling it in the REC market.

Among many South Korean regions, Jeju Island has been aggressively adopting renewable energy as a way of achieving carbon-free power generation by 2030. With these efforts, renewable energy in Jeju exceeded $48.7 \%$ of the total energy generation in the winter of 2018 [2]. Although the increasing renewable energy supply is eco-friendly, the high fraction of energy produced by intermittent renewable energy sources, such as wind and solar, affects the power system's stability and reliability $[3,4]$. The increase in renewable energy use can cause a reduction in the power system's inertia that is necessary for reliable operation. This reduced inertia can easily result in large frequency fluctuations. Jeju, where 
electricity has been mostly supplied by high-voltage direct current (HVDC) connected to the mainland, is especially vulnerable to the variability in energy supply caused by wind power [5,6].

Wind farm operators should follow a grid code, defined by regulators, to connect their wind farm to the power grid safely. The grid code includes requirements for additional controller installation to control the voltage at the connected node and support the grid with a contingency energy reserve [7]. Among the terms of the code, power variation at the point of common coupling (PCC) due to wind power fluctuations is a major concern of wind farm operators and power system operators. European countries have set power gradient limits in their grid codes as the contribution from renewable energy generation increases [8]. Furthermore, though renewables are considered to be the cheapest energy sources, excess renewable energy generation has to be curtailed for operational stability [9]. The ramping that occurs at the PCC should also be considered since the reserve and ramping components are secured to prevent power shortages [10]. Although there are no requirements stipulated in the grid code for wind power fluctuations in Korea, it is expected to recommend that the power variation at the PCC in a 5 min period does not exceed $5 \%$ of wind farm capacity.

Among the methods to mitigate power fluctuations, utilizing an energy storage system (ESS) is considered to be a key solution for the power system operation of large wind farms. [11]. An ESS can handle the power variability with flexible charging and discharging. In many studies, performance analyses were conducted under intermittent power systems with various ESS types, including flywheels, superconductors, and fuel cells. Among energy storage sources, the battery-based ESS (BESS) demonstrated a better performance [12]; its advanced technology and large market share were favorable for large offshore wind farms [13].

With these advantages, the operation and the planning methods for an ESS have been introduced to improve wind farm operations. The coordinated control method for ESS integration with wind turbines was proposed to reduce wind power fluctuations and to extend ESS lifespan [14]. An adaptive supervisory control scheme was designed for wind turbine-integrated systems and ESSs to improve power qualities [15]. Besides designing a control scheme, optimal ESS scheduling strategies have been proposed to improve contract fulfillment and to minimize the curtailment of renewable energy production under uncertain circumstances [16,17]. For efficient wind farm operation, it is important to determine the ESS's size and utilize it efficiently. Methodologies for choosing an adequate storage size have been proposed to handle ramping events and mitigate scheduling errors caused by intermittent power generation [18]. Determining an installation site for an ESS is a major consideration in planning the coordinated system under the stochastic nature of power generation and load [19,20]. Furthermore, an optimal management policy was designed to maximize benefits and select an optimal storage size [21]. In short, the proper operation and planning strategies of an ESS can help wind farm operators and power system operators minimize their operational costs under an intermittent power supply.

Korea has encouraged ESS installation on wind farms through the provision of subsidies. According to the revenue agreements for wind power generation and ESS discharging power, revenue is dependent on peak and off-peak periods [22]. The power provided by the PCC is sold at a system marginal price (SMP), and the wind power generation transmitted to the PCC can earn an REC credit at all periods. However, during peak periods, wind farm operators can obtain additional REC credits for power discharged from their ESS. With this incentive policy, wind farm operators might recoup their ESS installation investment. In reality, however, peak-biased incentives affect power system operations since wind farm operators discharge their ESS power only during peak periods when additional revenue can be earned [23]. Although the power output of wind farms can fluctuate at all times, the lack of incentive for utilizing the ESS during off-peak periods may increase power variability as wind energy penetration increases. Hence, considering peak-biased incentive policies, ESSs cannot adequately support the power system at all periods.

While power system operators agree that utilizing energy storage resources is important for stable system operation, no study has focused on the effect of peak-biased incentives on wind power fluctuations. To address this, we evaluated the interaction between imposing an REC multiplier 
for discharging power during off-peak periods and the number of power shortages under Korea's renewable energy policy. This study addresses the following aspects:

- A coordinated model of a wind farm with an ESS is constructed to model actual behaviors of wind farm operators;

- A revenue optimization problem is modeled as a mixed integer linear programming (MILP) problem based on the settlement rules of wind power generation;

- An objective function is modified to consider additional revenue obtained by discharging in off-peak periods; and

- The effect of imposing an additional incentive in off-peak periods is analyzed according to the REC multiplier magnitude.

The rest of this paper is organized as follows: Section 2 describes an optimization model of a wind farm with an ESS. The modified optimization model to induce discharge in off-peak periods is introduced in Section 3. The effects of an REC multiplier in off-peak periods on mitigating wind power fluctuations are analyzed through a case study in Section 4. We conclude in Section 5.

\section{An Optimization Model for Wind Farms with an ESS}

\subsection{Coordinated Model of Wind Farms with an ESS}

This study examined a coordinated model of an onshore wind farm with an ESS. The farm was connected to an electricity grid via the PCC as shown in Figure 1.

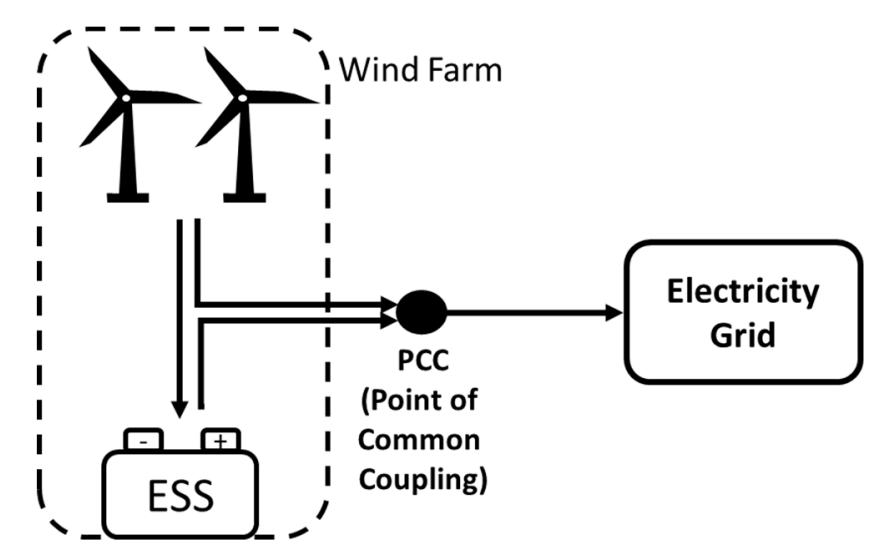

Figure 1. A coordinated model of a wind farm with an energy storage system (ESS).

Power generated from wind turbines can flow in two directions. One way is toward the ESS, where the power is used to charge the storage system. The rest of power is transmitted to the grid via the PCC. In other words, the power charge of the ESS comes only from wind power generation.

This model allows the wind farm operator to transmit and sell the generated electricity via the PCC to the main grid. The revenue from selling the electricity to the gird is comprised of two parts: first, is the income from wind power generation, excluding the power for battery-charging; and second, is the income from the ESS discharge.

This model assumes that the operator is not responsible for mitigating the resource variability since there are no penalties or incentives dependent on fluctuating wind power generation under the current policy.

\subsection{Objective Function}

Revenue and expense models were defined for describing the behaviors of the wind farm operator. The revenue models were composed of revenues in off-peak periods, $R_{t}^{o p k}$, and peak periods, $R_{t}^{p k}$. In 
the expense model, $C_{t}^{E S S}$, could vary with the total amount of charged and discharged power. Hence, the objective function is given by:

$$
\text { Maximize } \sum_{t \subset O f f \text { peak }} R_{t}^{o p k}+\sum_{t \subset p e a k} R_{t}^{p k}-\sum_{\forall t} C_{t}^{E S S} \forall t
$$

and, considering revenues in off-peak and peak periods and expense

$$
\begin{gathered}
R_{t}^{o p k}=P_{t}^{P C C} \times s m p_{t}+\left(P_{t}^{\text {wind }}-P_{t}^{c h}\right) \times R E C_{t} \forall t, \\
R_{t}^{p k}=P_{t}^{P C C} \times s m p_{t}+\left(P_{t}^{\text {wind }}-P_{t}^{c h}\right) \times R E C_{t}+\alpha \times P_{t}^{d c h} \times R E C_{t} \forall t, \\
C_{t}^{E S S}=\left(P_{t}^{c h}+P_{t}^{d c h}\right) \times \omega^{V O \& M} \forall t,
\end{gathered}
$$

where the power at the PCC, $P_{t}^{P C C}$, is described as

$$
P_{t}^{P C C}=P_{t}^{\text {wind }}-P_{t}^{c h}+P_{t}^{d c h} \forall t .
$$

The power at the PCC and the net power of the wind farm are paid out at the SMP and the REC price, respectively, regardless of the time period, as shown by the first and second variables of the right side of the Equations (2) and (3). The ESS discharged power during the peak period is paid out at the REC price by multiplying the REC multiplier, $\alpha$, as depicted by the third variable from the right side of Equation (3). The variable costs of operating the ESS is composed of variable operation and maintenance costs and the total amount of charging and discharging as shown in Equation (5).

Using this optimization problem, wind farm operators can maximize revenue by controlling the amount of ESS charged and discharged power.

\subsection{Operational Constraints of an ESS}

The ESS can charge and discharge power within its state of charge (SOC) limit. Hence, the SOC of the ESS, $S O C_{t}$, is limited by the minimum and maximum SOC levels:

$$
S O C^{\min } \leq S O C_{t} \leq S O C^{\max } \forall t .
$$

The charging-discharging operations determine the SOC and the initial SOC is assumed to be half of the storage capacity:

$$
S_{S O C}=\left\{\begin{array}{ll}
\operatorname{Cap}_{t}^{E S S} / 2+P_{t}^{c h} \times \eta^{E S S, e f f}-P_{t}^{d c h} / \eta^{E S S, e f f}, & \text { if } t=1 \\
S O C_{t-1}+P_{t}^{c h} \times \eta^{E S S, e f f}-P_{t}^{d c h} / \eta^{E S S, e f f}, & \text { otherwise }
\end{array} .\right.
$$

The ESS can only operate in charging-discharging mode at a single time-step as follows:

$$
\delta_{t}^{c h}+\delta_{t}^{d c h} \leq 1 \forall t
$$

The amount of discharging or charging power is limited by the capacity and the ESS charging-discharging efficiency. These characteristics are given by

$$
\begin{gathered}
0 \leq P_{t}^{c h} \leq \eta^{c h} \times \delta_{t}^{c h} \times \operatorname{Cap}^{E S S} / 5 \forall t \text { and } \\
0 \leq P_{t}^{d c h} \leq \eta^{d c h} \times \delta_{t}^{d c h} \times \operatorname{Cap}^{E S S} / 5 \forall t .
\end{gathered}
$$

The capacity multiplications and the ESS charging-discharging efficiency are divided by 5 since we assume that the ESS can be fully discharged or charged in 25 min [24]. 
The charging power can only be supplied from the wind farm when the following conditions are met:

$$
0 \leq P_{t}^{c h} \leq P_{t}^{\text {Wind }} \forall t
$$

\subsection{Variability Criteria for Wind Power Generation}

The variability is defined as the power deviation at the PCC in a 5-min time step. The grid code model for the variability is described as follows:

$$
-\sigma^{\mathrm{var}} \times C a p^{\text {Wind }} \leq P_{t}^{\text {wind }}-P_{t-1}^{P C C}-P_{t}^{c h}+P_{t}^{d c h}-P_{t}^{\text {Excess }}+P_{t}^{\text {Short }} \leq \sigma^{\mathrm{var}} \times \text { Cap }^{\text {Wind }} t=2,3, \cdots, t^{\text {max }},
$$

where $\sigma^{v a r}$ is the wind farm capacity ratio of the variation criteria, and $P_{t}^{\text {Excess }}$ and $P_{t}^{\text {Short }}$ are the surplus variables for the upward and downward power, respectively, that exceed the variation criteria. The power at the PCC at time step $t$ is defined by its representation in Equation (12) since the amount of ESS charging-discharging at time step $t$ can change the power deviation of the adjacent time step. The surplus variables should have a non-zero value only if the power deviation at the two adjacent time steps exceeds the variability criteria in the opposite sides of the equation. Additional constraints for these surplus variables are required since Equation (12) is insufficient to determine the surplus. These constraints are described as follows:

$$
\begin{gathered}
P_{t}^{\text {Excess }}=\delta_{t}^{\text {Excess }}\left(P_{t}^{\text {wind }}-P_{t-1}^{P C C}-P_{t}^{c h}-\sigma^{\mathrm{var}} \times \operatorname{Cap}^{\text {Wind }}\right) t=2,3, \cdots, t^{\text {max }} \text { and } \\
P_{t}^{\text {Short }}=\delta_{t}^{\text {Short }}\left(P_{t}^{\text {wind }}-P_{t-1}^{P C C}+P_{t}^{d c h}+\sigma^{\mathrm{var}} \times \operatorname{Cap}^{\text {Wind }}\right) t=2,3, \cdots, t^{\text {max }},
\end{gathered}
$$

where $\delta_{t}^{\text {Excess }}$ and $\delta_{t}^{\text {Short }}$ are binary variables representing the state of exceeding the upper and lower variation criteria, respectively, in time-step $t$. These variables are below 1 at a single time step, as follows:

$$
\delta_{t}^{\text {Excess }}+\delta_{t}^{\text {Short }} \leq 1 t=2,3, \cdots, t^{\max } .
$$

The surplus variables in Equations (13) and (14) mitigate the deviation between the wind farm generation at time step $t$ and the power at the PCC at time-step $t-1$, along with the charging/discharging power at time-step $t$. In short, the surplus variables are assumed to be control variables to mitigate the variability in wind power generation.

The process of determining the value of the surplus variables is described in Figure 2, where the power deviation and the upper and lower criteria are observed.

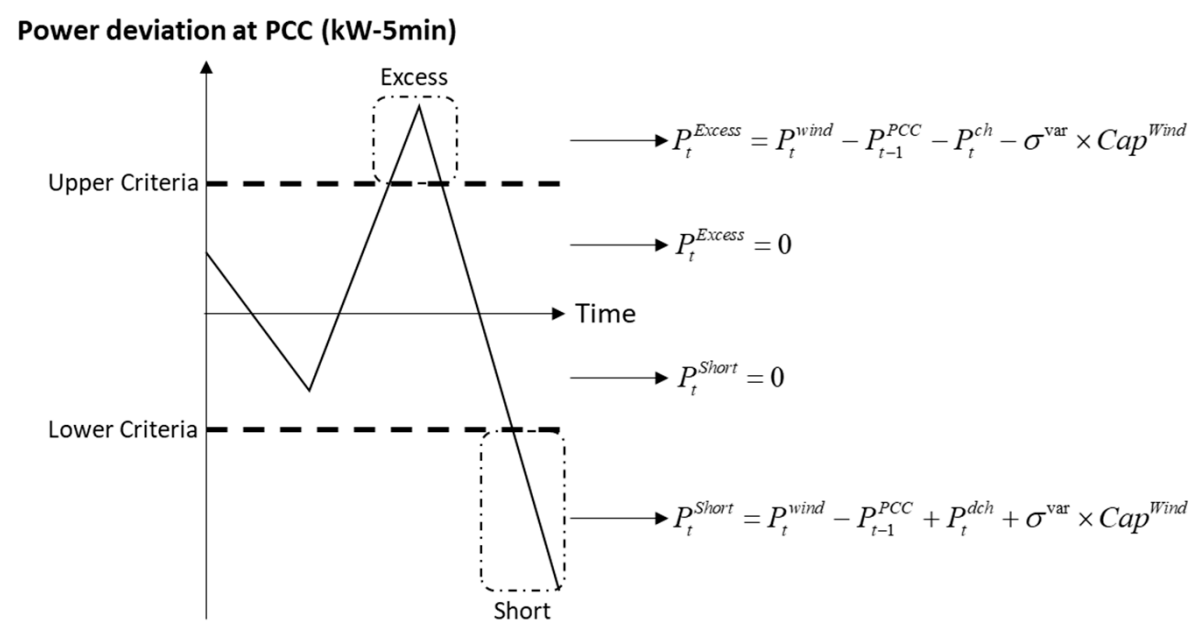

Figure 2. Determination of the surplus variable for power exceeding the upper and lower variation criteria. 
The surplus variables can be determined by the upper and lower criteria. If the power deviation (the solid line) is within the criteria (the dotted line), these variables must be zero since the deviation does not exceed the criteria. In this case, the variables in Equations (13) and (14) are zero since both variables in Equation (15) are zero. However, if the deviation is outside of the criteria, the surplus variables should be the amount of power exceeding the criteria. In this case, the excess power is equal to variables $P_{t}^{\text {Excess }}$ or $P_{t}^{\text {Short }}$ in Equation (13) or (14), since the binary variable, $\delta_{t}^{\text {Excess }}$ or $\delta_{t}^{\text {Short }}$, is 1 .

In this optimization problem, Equations (13) and (14) reflect the above process and are depicted as nonlinear constraints. Therefore, MILP constraint linearization is required, as described in Appendix A.

\section{A Modified Optimization Model to Induce the Discharge of an ESS in Off-Peak Periods}

\subsection{Modified Objective Function}

The off-peak period revenue could be modified in order to induce the charging and discharging operations by the wind farm operator. Hence, the modified objective function is defined as:

$$
\text { Maximize } \sum_{t \subset O f f \text { peak }} R_{t}^{\text {new_opk }}+\sum_{t \subset \text { peak }} R_{t}^{p k}-\sum_{\forall t} C_{t}^{E S S} \forall t
$$

and considering modified revenue

$$
R_{t}^{\text {new } \_o p k}=P_{t}^{P C C} \times s m p_{t}+\left(P_{t}^{\text {wind }}-P_{t}^{c h}\right) \times R E C_{t}+\alpha^{o p k} \times P_{t}^{d c h} \times R E C_{t} \forall t,
$$

where $\alpha^{o p k}$ is the REC multiplier for discharging power in off-peak periods. The additional revenue generated is reflected in the third variable on the right side of the Equation (17). The peak period revenue and the expense of the ESS operation are the same as in Equations (3) and (4).

Conditions for determining $\alpha^{\text {opk }}$ are necessary to define the modified revenue and validate the profit for the operator.

\subsection{Conditions for Determining REC Multiplier for Discharging Power in Off-Peak Periods}

The REC multiplier for the discharging power in off-peak periods must be at least more than a specified value to initiate discharging. Therefore, it is important to consider the conditions for determining this multiplier as follows:

1. Condition 1: The REC multiplier value is more than 1 ; and

2. Condition 2: The REC multiplier value is more than the product reciprocal of the parameters related to ESS operations.

Condition 1 is the most common for determining the REC multiplier. As shown in Figure 1, wind farm operators can utilize their power resource generation in two ways. First, the generation transmitted to the electricity grid via the PCC can be paid out at a one-REC credit in the off-peak period, based on the settlement rules. In contrast, power generation for the ESS results in no profit for the operators. Charging loss occurs in ESS operations since the charging efficiency, which is less than $100 \%$, governs the amount of charging power. In this case, the operators would sell their power generation to the main grid, rather than charge the battery, in order to increase revenue. Therefore, the REC multiplier value should be greater than 1 to be fully recognized as a whole power generation, regardless of charging loss.

Condition 2 is a supplemental condition for determining the REC multiplier, along with Condition 1. As shown in Equations (7), (9), and (10), the turnaround and discharging efficiency, as well as the charging efficiency, would result in a charging and discharging loss since these efficiencies are also less than $100 \%$. First, the power loss would occur during the charging operation, with an efficiency of $\eta^{c h}$. The second loss is incurred by the inner operations of the ESS, modeled with the turnaround efficiency of $\eta^{E S S}$, eff . Discharging loss occurs when the ESS discharges its power, with an efficiency 
of $\eta^{d c h}$. Although the power from the ESS and wind turbines both have the same effect of supplying electricity to the grid, the discharging power of the ESS is from partial wind power production with losses. The REC multiplier for the discharging power should be higher than that for the wind power to compensate for power losses. Hence, the minimum value for the REC multiplier in off-peak periods would be the reciprocal of the charging, turnaround, and discharging efficiencies.

\section{Case Study and Discussion}

The effectiveness of the proposed revenue model was evaluated by comparing the total discharge power and the total power exceeding the variation criteria with the conventional revenue model.

\subsection{Simulation Setup}

\subsubsection{Parameters of a Wind Farm and an ESS}

Operational data related to the coordinated model were required to simulate the coordinated wind farm model with an ESS as shown in Figure 1. The key parameters for the coordinated model operation are listed in Table 1.

Table 1. Key parameters of a wind farm and ESS operation.

\begin{tabular}{cc}
\hline Parameter & Value \\
\hline Wind Farm Capacity [kW] & 10,790 \\
ESS Capacity [kWh] & 2450 \\
SOC $^{\text {in }} /$ SOC $^{\text {max }}[\%]$ & $20 / 80$ \\
Turnaround efficiency [\%] & 90 \\
Charging/Discharging efficiency [\%] & $90 / 90$ \\
Variable O\&M cost of ESS [Won/kW-5 min] & 0.0275 \\
REC multiplier for discharging power in the peak period & 4.5 \\
\hline
\end{tabular}

The wind farm in Jeju Island is a 10,790 kW Haengwon offshore farm [25]. The ESS in the wind farm was assumed to be installed with an optimized capacity of $2450 \mathrm{kWh}$ [26]. The operation conditions for the ESS, regarding the minimum and maximum charge level, turnaround, and charging and discharging efficiency were assumed to be $90 \%$. In addition, the variable O\&M cost of ESS was adjusted to a five-minute time step unit [27]. The REC multiplier for the discharging power in peak periods followed the current RPS policy [22].

\subsubsection{Wind Farm Generation Profiles}

One-minute time step data for yearly wind power generation profiles were obtained from the Korea Power Exchange (KPX). The time step of these profiles was changed from one-minute to five-minute in order to match the optimization model time step. Additionally, characteristic days in these profiles were selected to decrease the computational burden. The selection procedure was as follows:

- The yearly data were sorted by month;

- Power exceeding the upper and lower variation criteria for daily wind power generation in the monthly profiles was calculated;

- The day with the highest number of occurrences beyond the variation criteria was chosen as a typical day in the monthly profile; and

- The above procedures were repeated for all months.

The selected dates, the number of violations of the variation criteria, the seasons, and months are listed in Table 2. The season was required to determine the REC multiplier during peak periods. In addition, the peak period for the REC multiplier is listed in the table. 
Table 2. The number of violations of the variation criteria and peak period for the renewable energy certificate (REC) multiplier.

\begin{tabular}{ccccc}
\hline Season & Month & Date & $\begin{array}{c}\text { Number of Violating } \\
\text { Variation Criteria }\end{array}$ & $\begin{array}{c}\text { Peak Period for } \\
\text { REC Multiplier }\end{array}$ \\
\hline Winter & 1 & 01.20 & 34 & \\
Winter & 2 & 02.10 & 26 & $18: 00 \sim 21: 00$ \\
Winter & 3 & 03.08 & 18 & \\
\hline Spring & 4 & 04.17 & 15 & $19: 00 \sim 22: 00$ \\
Spring & 5 & 05.09 & 10 & \\
Spring & 6 & 06.06 & 10 & $13: 00 \sim 15: 00$, \\
\hline Summer & 7 & 07.02 & 6 & $19: 00 \sim 21: 00$ \\
Summer & 8 & 08.20 & 10 & $18: 00 \sim 21: 00$ \\
Summer & 9 & 09.07 & 9 & $18: 00 \sim 21: 00$ \\
\hline Autumn & 10 & 10.01 & 18 & 17 \\
\hline Winter & 11 & 11.24 & 32 & \\
Winter & 12 & 12.05 & &
\end{tabular}

As shown in Table 2, the number of violations of the variation criteria in winter tended to be greater than in other seasons. It was expected that the wind in winter on Jeju Island was stronger than the winds in other seasons. As expected, the variation in wind power generation at each five-minute time step in winter tended to be greater than that in other seasons, as shown in Figure 3.
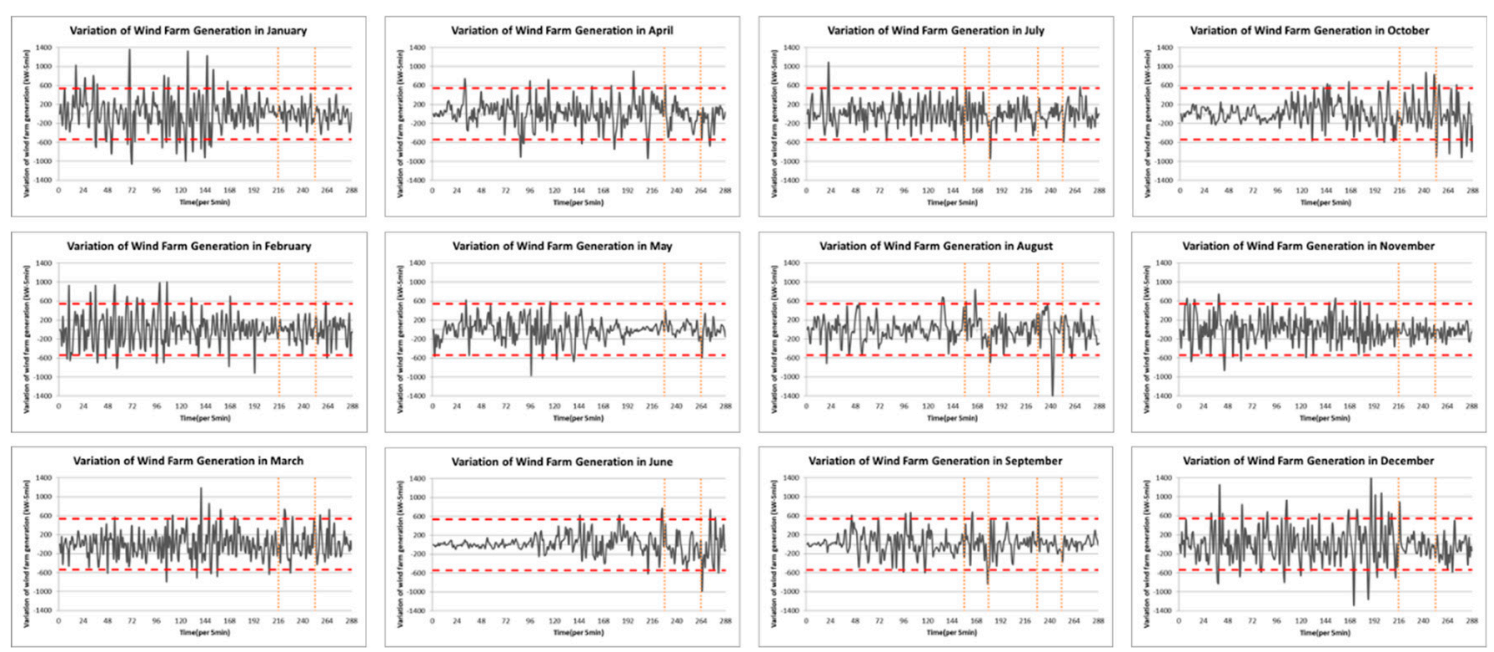

Figure 3. Profiles of wind power generation variation at each 5-min time step for each month based on one-year historical data at the Haengwon wind farm.

Figure 3 shows the variation profiles in rows from left to right in monthly order. The red dotted lines represent the variation criteria value. The gap between the yellow dotted lines signifies the peak period. Unlike other seasons, the wind power generation variation was unstable in winter from January to March and from November to December. The variation profiles in other seasons were mostly within the criteria. There were no noticeable trends in the variation profiles except in terms of seasons.

\subsubsection{SMP and REC Price}

The historical data for the yearly SMP and REC price was obtained for a one-hour time step [28,29]. Although the historical price differed both hourly and monthly, the average monthly price was calculated to reduce the variable price effect on the simulation, as shown in Table 3. 
Table 3. Monthly average system marginal price (SMP) and REC price data.

\begin{tabular}{ccc}
\hline Month & $\begin{array}{c}\text { Average System Marginal Price } \\
\text { [Won/kW-5 min] }\end{array}$ & $\begin{array}{c}\text { Average REC Price } \\
\text { [Won/kW-5 min] }\end{array}$ \\
\hline 1 & 8.85 & 20.51 \\
2 & 10.6 & 17.72 \\
3 & 11.06 & 17.49 \\
4 & 10.11 & 17.28 \\
5 & 10 & 19.07 \\
6 & 10.39 & 17.38 \\
7 & 10.12 & 17.92 \\
8 & 9.39 & 17.88 \\
9 & 9 & 19 \\
10 & 8.87 & 16.44 \\
11 & 10.79 & 18.05 \\
12 & 10.77 & 14.59 \\
\hline
\end{tabular}

The average REC price was nearly twice the average system marginal price. According to the table, the unit price was applied monthly in the simulation.

\subsection{Case Study}

\subsubsection{Case Setup}

The proposed MILP optimization problems were implemented in GAMS 25.1.2 and solved using GUROBI 8.0. The dual simplex algorithm terminated after reaching a $1 \%$ duality gap. This case study was conducted to compare the discharging power, the amount of excess power, and the total net revenue for the wind farm operator to determine whether to consider the REC multiplier in off-peak periods. When considering the REC multiplier, its values were listed by size, as shown in Table 4 .

Table 4. Summary of the case setup.

\begin{tabular}{ccc}
\hline Case Number & $\begin{array}{c}\text { Status of REC Multiplier } \\
\text { in Off-Peak Period }\end{array}$ & Magnitude of REC Multiplier \\
\hline 1 & $\mathrm{X}$ & - \\
2 & $\mathrm{O}$ & 1 \\
$2-1$ & $\mathrm{O}$ & 1.4 \\
$2-2$ & $\mathrm{O}$ & 3 \\
$2-3$ & $\mathrm{O}$ & 4.5 \\
\hline
\end{tabular}

Case 1 is the reference case describing the current state of the wind farm operation without imposing the REC multiplier. Case 2 was the first control case where the REC multiplier was 1 for validating condition 1 as described in Section 3.2. The REC multiplier in case 2-1 was calculated by rounding up the reciprocal of charging, discharging, and turnaround efficiencies to two decimal places based on condition 2 as described in Section 3.2. Cases 2-2 and 2-3 were additional control cases for comparing the results with the increasing REC multiplier.

\subsubsection{Case Results}

From the power system operator's perspective, power shortages might be a major concern in operations since the shortage has to be supplemented by operating additional power resources. However, surplus power can be easily handled by curtailing wind power generation. Thus, the operator would pay attention to discharging patterns when power shortages occur. Therefore, this study focused on representing the results, including when the power exceeded the lower variation criteria and the discharging power.

The average discharging power in off-peak and peak periods was estimated to evaluate the effect of applying the REC multiplier, as depicted in Table 5. 
Table 5. Average monthly discharging power in off-peak and peak periods.

\begin{tabular}{ccccccccc}
\hline \multirow{2}{*}{ Month } & \multicolumn{3}{c}{$\begin{array}{c}\text { Average Discharging Power } \\
\text { during Off-Peak Periods }\end{array}$} & \multicolumn{4}{c}{$\begin{array}{c}\text { Average Discharging Power } \\
\text { during Peak Periods }\end{array}$} \\
\cline { 2 - 9 } & Case 1 \& Case 2 & Case 2-1 & Case 2-2 & Case 2-3 & Case 1 \& Case 2 & Case 2-1 & Case 2-2 & Case 2-3 \\
\hline 1 & 0 & 163.8 & 158.5 & 160.5 & 182.4 & 182.9 & 172.8 & 130.2 \\
2 & 0 & 156.7 & 157.4 & 129.4 & 184.5 & 187.2 & 137.2 & 71.5 \\
3 & 0 & 160.6 & 161.1 & 161.3 & 182 & 179.9 & 155.5 & 161.7 \\
4 & 0 & 110.4 & 153.3 & 151.1 & 181.3 & 181.3 & 172.5 & 152.5 \\
5 & 0 & 155.6 & 162.2 & 166.8 & 179.1 & 179.3 & 179.3 & 146.4 \\
6 & 0 & 138.7 & 155.8 & 155.8 & 183.1 & 183.9 & 178.7 & 152.6 \\
7 & 0 & 158 & 152 & 147 & 183.5 & 198.9 & 175.2 & 169.2 \\
8 & 0 & 154.4 & 157.5 & 157.7 & 186.7 & 190.3 & 186.3 & 180.6 \\
9 & 0 & 151.9 & 152.6 & 149.9 & 192.1 & 191.3 & 192.1 & 183.1 \\
10 & 0 & 147.8 & 148.5 & 151.8 & 178.4 & 180.4 & 178.2 & 153.6 \\
11 & 0 & 121.7 & 158.7 & 161.4 & 181 & 182.6 & 163.5 & 148 \\
12 & 0 & 163.8 & 155.1 & 163.2 & 177.3 & 178.8 & 164.8 & 142.3 \\
\hline Total & 0 & 147.2 & 156.1 & 154.7 & 182.6 & 184.7 & 171.3 & 149.3 \\
Average & 0 & & & & & & & \\
\hline
\end{tabular}

ESS operations under current policies could be modeled by case 1. As shown in Table 5, the ESS did not discharge in off-peak periods, while it discharged in peak periods. As expected, results of cases 1 and 2 are same. The results of the discharging power are first observed in case 2-1. In addition, the average discharging power during the peak period in case 2-1 was slightly higher than that in cases 1 and 2. This discharging power was presumed to increase due to altered ESS operations in the off-peak period. The average discharging power in the off-peak period in case 2-2 was higher than in case 2-1 due to an increased REC multiplier. However, the average discharging power in the peak period in case 2-2 was lower than that in case 2-1. These results are presumed to be due to the increase in discharging power during the off-peak period. Case 2-3 exhibited different trends. The average discharging power during the off-peak period in case 2-3 was slightly lower than that in Case 2-2. This result was compared with the increasing trend that existed in the discharging power during the off-peak period in cases 2-1 and 2-2. The average discharging power in the peak period in case 2-3 was lower than in the other cases.

The amount of power that exceeded the lower variation criteria is presented in Table 6 . The effect of the REC multiplier on the power shortage is examined based on these case results.

Table 6. Monthly power exceeding the lower variation criteria of the point of common coupling (PCC) in off-peak and peak periods.

\begin{tabular}{|c|c|c|c|c|c|c|c|c|}
\hline \multirow[t]{2}{*}{ Month } & \multicolumn{4}{|c|}{$\begin{array}{l}\text { Average Value of Power Exceeding } \\
\text { the Lower Variation Criteria of PCC } \\
\text { in the Off-Peak Period }\end{array}$} & \multicolumn{4}{|c|}{$\begin{array}{l}\text { Average Value of Power Exceeding } \\
\text { the Lower Variation Criteria of PCC } \\
\text { in the Peak Period }\end{array}$} \\
\hline & Case $1 \&$ Case 2 & Case 2-1 & Case 2-2 & Case 2-3 & Case 1 \& Case 2 & Case 2-1 & Case 2-2 & Case 2-3 \\
\hline 1 & 45.16 & 18.01 & 17.85 & 16.53 & 14.81 & 0 & 0 & 0 \\
\hline 2 & 27.37 & 6.07 & 10.31 & 3.02 & 0 & 0 & 0 & 0 \\
\hline 3 & 7.96 & 0 & 0 & 2.48 & 16.3 & 25.3 & 16.3 & 0 \\
\hline 4 & 17.9 & 14.38 & 20.7 & 7.74 & 19.35 & 19.35 & 0 & 0 \\
\hline 5 & 16.02 & 10.17 & 7.25 & 2.68 & 15.5 & 15.5 & 15.5 & 0 \\
\hline 6 & 8.72 & 8.08 & 0 & 12.02 & 19.48 & 18.58 & 18.85 & 41.12 \\
\hline 7 & 8.8 & 9.73 & 3.98 & 7.29 & 12.11 & 0 & 12.1 & 13.93 \\
\hline 8 & 8.47 & 11.02 & 8.24 & 7.89 & 61.67 & 61.29 & 33.62 & 18.43 \\
\hline 9 & 5 & 3.99 & 2.77 & 4.91 & 49.15 & 49.15 & 49.15 & 25.58 \\
\hline 10 & 12.88 & 5.6 & 12.45 & 10.73 & 29.58 & 24.18 & 31.01 & 0 \\
\hline 11 & 11.03 & 13.03 & 2.47 & 5.78 & 38.86 & 19.04 & 0 & 0 \\
\hline 12 & 31.57 & 21.95 & 21.53 & 16.96 & 17.87 & 34.51 & 19.88 & 0 \\
\hline $\begin{array}{c}\text { Total } \\
\text { Average }\end{array}$ & 16.74 & $\begin{array}{c}10.17 \\
(\downarrow 39.3 \%)\end{array}$ & $\begin{array}{c}8.96 \\
(\downarrow 46.5 \%)\end{array}$ & $\begin{array}{c}8.17 \\
(\downarrow 51.2 \%)\end{array}$ & 24.56 & $\begin{array}{c}22.24 \\
(\downarrow 9.4 \%)\end{array}$ & $\begin{array}{c}16.37 \\
(\downarrow 33.3 \%)\end{array}$ & $\begin{array}{c}8.26 \\
(\downarrow 66.4 \%)\end{array}$ \\
\hline
\end{tabular}


In the off-peak period, ESS operations rarely affected the average power shortage in cases 1 and 2. The results of case 2-1, when the ESS begins discharging power, showed that the shortage was significantly reduced during the winter months. Furthermore, these monthly results demonstrated unique increments. Although there was a slight lack of consistency in the results, the total average power shortages decreased by almost 39\% for cases 1 and 2 . Similarly, in cases $2-2$ and 2-3, the average value of power exceeding the lower variation criteria decreased, and the total average power for cases 1 and 2 reduced by almost $47 \%$ and $51 \%$, respectively. The trends in power exceeding the variation criteria in the peak period are similar to those in the other period. Although the amount of discharging power seemed greater during the peak period, as shown in Table 5, the average power shortage in cases 1 and 2 were relatively larger in the peak period than those in the off-peak period. The shortages had a high value during the summer months since the peak period was longer than in other seasons. Contrary to the case trend of a decreasing discharging power during the peak period, the average value of power shortages decreased. In short, although the REC multiplier in the peak period was unchanged, the number of power shortages tended to decrease. These results imply that changes in the off-peak period would result in changes in the peak period by discharging power when the wind power fluctuations are significant.

The total monthly net revenue is presented in Table 7. Although the total net revenue results did not show a direct effect on mitigating the variation in wind power generation, the results suggest the effects of the additional incentive on the total net revenue.

Table 7. Total net revenue results.

\begin{tabular}{ccccc}
\hline Month & $\begin{array}{c}\text { Case } \mathbf{1} \text { \& Case } \mathbf{2} \\
{\left[\mathbf{1 0}^{\mathbf{3}} \text { Won }\right]}\end{array}$ & $\begin{array}{c}\text { Case 2-1 } \\
{\left[\mathbf{1 0}^{\mathbf{3}} \mathbf{W o n}\right]}\end{array}$ & $\begin{array}{c}\text { Case 2-2 } \\
{\left[\mathbf{1 0}^{\mathbf{3}} \mathbf{W o n}\right]}\end{array}$ & $\begin{array}{c}\text { Case 2-3 } \\
{\left[\mathbf{1 0} \mathbf{3}^{\mathbf{3}} \mathbf{W o n}\right]}\end{array}$ \\
\hline 1 & 56,027 & 56,080 & 57,360 & 58,513 \\
2 & 62,766 & 62,787 & 63,804 & 64,331 \\
3 & 57,057 & 57,068 & 58,164 & 59,255 \\
4 & 36,255 & 36,262 & 37,324 & 38,263 \\
5 & 21,344 & 21,354 & 22,494 & 23,558 \\
6 & 32,043 & 32,060 & 33,132 & 34,094 \\
7 & 42,325 & 42,589 & 43,782 & 44,851 \\
8 & 29,355 & 29,642 & 31,059 & 32,360 \\
9 & 27,149 & 27,430 & 28,834 & 30,055 \\
10 & 39,275 & 39,293 & 40,318 & 41,292 \\
11 & 35,039 & 35,054 & 36,126 & 37,171 \\
12 & 38,463 & 38,488 & 39,574 & 40,688 \\
\hline
\end{tabular}

In Section 3.2, the results of Cases 1 and 2 are the same since the REC multiplier of 1 in off-peak periods could not induce discharging power. The revenue in case 2-1 increased slightly $(0.01-1.02 \%)$. The REC multiplier applied in case 2-2 increased the revenue for cases 1 and 2 by $1.6-5.8 \%$, and by $1.6-5.1 \%$ for case $2-1$. Although the REC multiplier in case 2-2 was double that in case 2-1, a drastic revenue increase was not observed as the amount of the discharging power was assumed to be limited by the discharging rate. In case $2-3$, the revenue was higher by $2.4-9.4 \%$ for cases 1,2 , and $2-1$, and by $0.8-4.5 \%$ for case $2-2$.

\subsection{Discussions}

The proposed revenue model for wind farms could reflect the current RPS policy in Korea as shown in results of case 1. From the other results, applying the REC multiplier in off-peak periods could be considered as a factor in reducing power shortages. This incentive would have a positive effect on mitigating wind power fluctuations. It might be also act as an economic strategy for power system operators since the additional revenue did not increase significantly, even when the magnitude of the REC multiplier was increased more than three-fold. Hence, the proposed incentive mechanism is a win-win proposition for wind farm and power system operators. 
Further studies are required to analyze the operations and control strategies of ESSs since the proposed model was mainly designed for simulating revenue generation. The above results would be greatly influenced by the operation conditions of the ESS including SOC and charging and discharging rates. Although wind farm operators had the chance to gain more revenue as the REC multiplier increased, the additional revenue was limited since the amount of charging/discharging power was limited by these conditions. This limitation was considered as a factor in slight revenue increase despite a significant increase in the REC multiplier. Moreover, the proposed model could not show the optimal REC multiplier for both wind farm operators and power system operators. Therefore, future studies need to be designed to construct an optimization problem that reflects the detailed operations of the ESS and determines the optimal REC multiplier to control the power fluctuations.

\section{Conclusions}

This study evaluated the effect of an REC incentive on ESS operations to mitigate the variation in wind farm power generation on Jeju Island. We designed a coordinated model of the wind farm with an ESS to model the actual behaviors of a wind farm operator. From this model, an optimization problem was developed to maximize revenue for the operator. The objective function reflected the revenue from the SMP and the REC. The REC revenue function accounted for the discharging power, which paid out only in peak periods. Hence, the REC multiplier for discharging power in off-peak periods was applied to the modified REC revenue function. The conditions for determining the REC multiplier for the discharging power in off-peak periods were defined as they had not been previously accounted for. The problem constraints included the operational constraints of the ESS and the variability criteria for wind power generation. The linearization process was applied to the constraints of the variability criteria to be modeled as an MILP problem. Typical days in the one-year generation profiles were selected by using the variation criteria in order to ease the computational burden. Through the case studies, the modified revenue model induced ESS discharging in off-peak periods and reduced the average value of the power shortages without significant cost increases. We expect that applying the REC multiplier in off-peak periods would help wind farm and power system operators under intermittent renewable generation.

Author Contributions: All the authors contributed to this work. W.K. and J.L. designed the study and searched related researches. W.K. performed the analysis and wrote the first draft of the paper. J.K. contributed to the conceptual approach and thoroughly revised the paper.

Acknowledgments: This work was supported by the Korea Institute of Energy Technology Evaluation and Planning (KETEP) and the Ministry of Trade, Industry \& Energy (MOTIE) of the Republic of Korea (No. 20181210301380).

Conflicts of Interest: The authors declare no conflict of interest.

\section{Nomenclature}

Indices and Sets

$t$

$T$

Off peak $\subset T$

Peak $\subset$ T

Parameters

smpt

$R E C_{t}$

$P_{t}^{\text {Wind }}$

Cap Wind

$\sigma^{\mathrm{Var}}$

Cap ESS 5-min time step in $T$.

Set of time steps.

Subset of off-peak period.

Subset of peak period.

System marginal price at time, $t,(\mathrm{Won} / \mathrm{kW}-5 \mathrm{~min})$.

Price of renewable energy certificate at time, $t(\mathrm{Won} / \mathrm{kW}-5 \mathrm{~min})$.

Wind farm power generation at time, $t(\mathrm{~kW}-5 \mathrm{~min})$.

Capacity of the wind farm $(\mathrm{kW})$.

Variation criteria of the point of common coupling (PCC).

Capacity of the energy storage system $(\mathrm{kWh})$. 


$\omega^{V O \& M}$
$S O C^{\min } / S O C^{\max }$
$\eta^{E S S, e f f}$
$\eta^{c h} / \eta^{d c h}$
$\alpha$
$\alpha^{\text {opk }}$
$\mathrm{Z}$
Variables
$R_{t}^{\text {opk }}$
$R_{t}^{\text {pk }}$
$C_{t}^{E S S}$
$P_{t}^{P C C}$
$P_{t}^{c h} / P_{t}^{d c h}$
$S O C_{t}$
$P_{t}^{E x c e s s} / P_{t}^{S h o r t}$

Binary Variables $\delta_{t}^{c h} / \delta_{t}^{d c h}$ $\delta_{t}^{\text {Excess }} / \delta_{t}^{\text {Short }}$
Variable O\&M cost of energy storage system (Won/kW-5 min).

Minimum/maximum state of charge level of the energy storage system (kWh).

Turnaround efficiency of the energy storage system.

Charging/discharging efficiency of the energy storage system

Renewable energy certificate multiplier

Renewable energy certificate multiplier in the off-peak period

Positive infinity

Revenue in the off-peak period at time, $t$.

Revenue in the peak period at time, $t$.

Operational cost of the energy storage system at time, $t$.

Power of the point of common coupling (PCC) at time, $t$.

Charging/discharging power of the energy storage system at time, $t$.

State of charge of the energy storage system at time, $t$.

Surplus variable for the power exceeding the upper/lower variation criteria of the point of common coupling (PCC) at time, $t$.

Status of the charging/discharging operation of energy storage system at time, $t$. Status of exceeding the upper/lower variation criteria of the point of common coupling (PCC) at time, $t$.

\section{Appendix A The Linearization Process of Nonlinear Constraints for Determining the Surplus Variable for Power Exceeding Upper-Lower PCC Variation Criteria}

Equations (13) and (14) show the nonlinear constraints that determine the amount of power exceeding the upper and/or lower variation criteria. The right-side variables of these equations can be expressed as follows:

$$
\begin{aligned}
& \left\{\begin{array}{l}
P_{t}^{\text {Excess }} \geq P_{t}^{\text {wind }}-P_{t-1}^{P C C}-P_{t}^{\text {ch }}-\sigma^{\mathrm{var}} \times \text { Cap }{ }^{\text {Wind }}-\left(1-\delta_{t}^{\text {Excess }}\right) \cdot Z \\
P_{t}^{\text {Excess }} \leq P_{t}^{\text {wind }}-P_{t-1}^{P C C}-P_{t}^{c h}-\sigma^{\text {var }} \times C a p^{\text {Wind }}+\left(1-\delta_{t}^{\text {Excess }}\right) \cdot Z
\end{array} \quad t=2,3, \cdots, t^{\text {max }},\right. \\
& \left\{\begin{array}{c}
P_{t}^{\text {Excess }} \geq-\delta_{t}^{\text {Excess }} \cdot Z \\
P_{t}^{\text {Excess }} \leq \delta_{t}^{\text {Excess }} \cdot Z
\end{array} \quad t=2,3, \cdots, t^{\text {max }},\right. \\
& \left\{\begin{array}{l}
P_{t}^{\text {Short }} \geq P_{t}^{\text {wind }}-P_{t-1}^{P C C}+P_{t}^{d c h}+\sigma^{\mathrm{var}} \times C a p^{\text {Wind }}-\left(1-\delta_{t}^{\text {Short }}\right) \cdot Z \\
P_{t}^{\text {Short }} \leq P_{t}^{\text {wind }}-P_{t-1}^{P C C}+P_{t}^{d c h}+\sigma^{\mathrm{var}} \times C a p^{\text {Wind }}+\left(1-\delta_{t}^{\text {Short }}\right) \cdot Z
\end{array} \quad t=2,3, \cdots, t^{\text {max }},\right. \\
& \left\{\begin{array}{c}
-P_{t}^{\text {Short }} \geq-\delta_{t}^{\text {Short }} \cdot Z \\
-P_{t}^{\text {Short }} \leq \delta_{t}^{\text {Short }} \cdot Z
\end{array} \quad t=2,3, \cdots, t^{\text {max }} .\right.
\end{aligned}
$$

For the linearization process, either $\delta_{t}^{\text {Excess }}$ or $\delta_{t}^{\text {Short }}$ is equal to 0 if the power deviation at the PCC, expressed by $\left(P_{t}^{\text {wind }}-P_{t-1}^{P C C}-P_{t}^{c h}\right)$ or $\left(P_{t}^{\text {wind }}-P_{t-1}^{P C C}+P_{t}^{d c h}\right)$, does not exceed the variation criteria, expressed by $\left(\sigma^{\text {var }}\right.$. Cap $\left.{ }^{\text {Wind }}\right)$. Then, the variable for the excessive power $\left(P_{t}^{\text {Excess }}\right.$ or $\left.P_{t}^{\text {Short }}\right)$ is 0, as shown in Equations (A2) and (A4). Otherwise, either $\delta_{t}^{\text {Excess }}$ or $\delta_{t}^{\text {Short }}$ is equal to 1 . The power variable has a non-zero value as shown in Equations (A1) and (A3).

\section{References}

1. Jung, T.Y.; Kim, H.J. A critical review of the renewable portfolio standard in Korea. Int. J. Energy Res. 2016, 40, 572-578. [CrossRef]

2. Energy \& Environment News. Renewable Energy Supplying Half Of Total Electricity Consumption in Jeju Island. Available online: http://www.e2news.com/news/articleView.html?idxno=204758 (accessed on 16 January 2019).

3. Jeju Energy Corporation. Q3 2018 Renewable Energy Plant Status. Available online: http://www.jejuenergy.or.kr/index.php/contents/open/development/development01?act=view\&seq= $1351 \&$ bd_bcid=development\&page=1 (accessed on 17 January 2019).

4. Nguyen, N.; Mitra, J. Reliability of Power System with High Wind Penetration Under Frequency Stability Constraint. IEEE Trans.Power Syst. 2018, 33, 985-994. [CrossRef] 
5. Yoon, M.; Yoon, Y.-T.; Jang, G. A Study on Maximum Wind Power Penetration Limit in Island Power System Considering High-Voltage Direct Current Interconnections. Energies 2015, 8, 14244-14259. [CrossRef]

6. Chang, B.; Ha, Y.; Jeon, W. Jeju Island System Planning Considering Wind Power Penetration with HVDC Links. J. Int. Counc. Electr. Eng. 2011, 1, 287-291. [CrossRef]

7. IRENA. Available online: https://www.irena.org/publications/2016/May/Scaling-up-Variable-RenewablePower-The-Role-of-Grid-Codes (accessed on 22 January 2019).

8. Ikni, D.; Bagre, A.O.; Camara, M.B.; Dakyo, B. An offshore wind farm energy injection mastering using aerodynamic and kinetic control strategies. E3S Web Conf. 2018, 61, 00002. [CrossRef]

9. Collins, S.; Deane, P.; Ó Gallachóir, B.; Pfenninger, S.; Staffell, I. Impacts of Inter-annual Wind and Solar Variations on the European Power System. Joule 2018, 2, 2076-2090. [CrossRef] [PubMed]

10. California ISO. Flexible Ramping Product Uncertainty Calculation and Implementation Issues. Available online: https://www.caiso.com/Documents/FlexibleRampingProductUncertaintyCalculationImplementationIssues. pdf (accessed on 22 January 2019).

11. Zhao, H.; Wu, Q.; Hu, S.; Xu, H.; Rasmussen, C.N. Review of energy storage system for wind power integration support. Appl. Energy 2015, 137, 545-553. [CrossRef]

12. Mahto, T.; Mukherjee, V. Energy storage systms for mitigating the variability of isolated hybrid power system. Renew. Sustain. Energy Rev. 2015, 51, 1564-1577. [CrossRef]

13. Wang, X.; Li, L.; Palazoglu, A.; El-Farra, N.H.; Shah, N. Optimization and control of offshore wind systems with energy storage. Energy Conv. Manag. 2018, 173, 426-437. [CrossRef]

14. Kim, C.; Muljadi, E.; Chung, C.C. Coordinated Control of Wind Turbine and Energy Storage System for Reducing Wind Power Fluctuation. Energies 2018, 11, 52. [CrossRef]

15. Meghni, B.; Dib, D.; Azar, A.T.; Saadoun, A. Effective supervisory controller to extend optimal energy management in hybrid wind turbine under energy and reliability constraints. Int. J. Dyn. Control 2018, 6, 369-383. [CrossRef]

16. Damiano, A.; Gatto, G.; Marongiu, I.; Porru, M.; Serpi, A. Real-Time Control Strategy of Energy Storage Systems for Renewable Energy Sources Exploitation. IEEE Trans. Sustain. Energy 2014, 5, 567-576. [CrossRef]

17. Choi, S.; Min, S. Optimal Scheduling and Operation of the ESS for Prosumer Market Environment in Grid-Connected Industrial Complex. IEEE Trans. Ind. Appl. 2018, 54, 1949-1957. [CrossRef]

18. Hartmann, B.; Dán, A. Methodologies for Storage Size Determination for the Integration of Wind Power. IEEE Trans. Sust. Energy 2014, 5, 182-189. [CrossRef]

19. Nick, M.; Cherkaoui, R.; Paolone, M. Optimal siting and sizing of distributed energy storage systems via alternating direction method of multipliers. Int. J. Electr. Power Energy Syst. 2015, 72, 33-39. [CrossRef]

20. Delgado-Antillón, C.P.; Domínguez-Navarro, J.A. Probabilistic siting and sizing of energy storage systems in distribution power systems based on the islanding feature. Electr. Power Syst. Res. 2018, 155, 225-235. [CrossRef]

21. Choi, D.G.; Min, D.; Ryu, J.-H. Economic Value Assessment and Optimal Sizing of an Energy Storage System in a Grid-Connected Wind Farm. Energies 2018, 11, 591. [CrossRef]

22. Korea Energy Agency. Renewable Portfolio Standards(RPS). Available online: http://www.energy.or.kr (accessed on 13 December 2018).

23. Energy \& Environmental News. Dilemma on Integrating the ESS with the Wind Farm in Jeju Island. Available online: http://www.e2news.com/news/articleView.html?idxno=94724 (accessed on 22 January 2019).

24. Samsung SDI. ENERGY STORAGE SYSTEM for Utility, Commercial. Available online: http: //www.samsungsdi.co.kr/upload/ess_brochure/ESS\%20for\%20Utility\%20Commercial.pdf (accessed on 14 December 2018).

25. Jeju Energy Corporation. Wind Facilities. Available online: http://www.jejuenergy.or.kr/index.php/contents/ energy/facilities (accessed on 14 December 2018).

26. Kang, M.-S.; Jin, K.-M.; Kim, E.-H.; Oh, S.-B.; Lee, J.-M. A Study on the Determining ESS Capacity for Stabilizing Power Output of Haeng-won Wind Farm in Jeju. J. Korean Solar Energy Soc. 2012, 32, 25-31. [CrossRef] 
27. Platte River Power Authority. Battery Energy Storage Technology Assessment. Available online: https: //www.prpa.org/wp-content/uploads/2017/10/HDR-Battery-Energy-Storage-Assessment.pdf (accessed on 14 December 2018).

28. Korea Power Exchange. REC Price. Available online: http://onerec.kmos.kr/portal/rec/selectRecReport_ tradePerformanceList.do?key=1971 (accessed on 14 December 2018).

29. Korea Power Exchange. SMP for Jeju. Available online: http://www.kpx.or.kr/www/contents.do?key=226 (accessed on 14 December 2018). 